\title{
Death, Immortality, and Meaning in Life: Precis and Further Reflections
}

\author{
John Martin Fischer ${ }^{1}$
}

Received: 7 June 2021 / Accepted: 15 January 2022 / Published online: 12 February 2022

(C) The Author(s) 2022

\begin{abstract}
I offer an overview of the book, Death, Immortality, and Meaning in Life, summarizing the main issues, arguments, and conclusions (Fischer 2020). I also present some new ideas and further developments of the material in the book. A big part of this essay is drawing connections between the specific issues treated in the book and those in other areas of philosophy, and in particular, the theory of agency and moral responsibility. I highlight some striking similarities of both structure and content between the death/meaning in life literature and the free will/moral responsibility literature.
\end{abstract}

Keywords Death · Epicurus - Lucretius - Nagel · Meaning in life · Narrative Immortality $\cdot$ Near-death experiences $\cdot$ Williams

One might say, with some degree of oversimplification, that human beings have (at least) two basic drives: management of our anxieties about death and finding meaning in life. (Sex would be up there too!) Ernest Becker (1997) described the first as "terror management," and Victor Frankl (2006) highlighted the human quest for meaning. Of course, neither was the first to identify these forces, but they are salient modern presentations of the ideas. My book (Fischer 2020) is essentially organized around these two drives.

The following is a brief overview of the book, with sketches of the main arguments and conclusions. I also include some "further reflections," including material I have published after the book. These thoughts help to put the book in a larger context by connecting it to related debates. I highlight the relationships between the issues pertaining to death/meaning of life and agency (free will and moral responsibility). I

John Martin Fischer

john.fischer@ucr.edu

1 Department of Philosophy, University of California, 92521 Riverside, CA, USA 
also seek to build on some of the views in the book to show how they can be developed further. This essay is not just a summary, but an essay in which I attempt to make new contributions.

\section{Meaning in Life}

We typically (although not always) take premature death to be bad for the individual who dies - especially for those beings (like us) capable of living meaningful lives. Indeed, premature death is sometimes thought to be a tragedy for the deceased. (I will return to these assumptions of "common sense" in discussing death's putative badness.) There is thus an important connection between the special badness of death for the deceased and the capacity for meaning in life, although I do not contend that death can be a bad thing only for those capable of leading meaningful lives.

I agree with Susan Wolf (2010) and others that there is no meaning of life for human beings in general, but I do think (unlike Wolf, as far as I can see) that there can be a meaning of a particular individual's life. I hold that we can associate the meaning of an individual's life with the content of her "life-story" or "narrative" (interpreted strictly). I further hold that it is important and illuminating to distinguish the meaning of an individual's life from the level of meaningfulness of the life. They are two interrelated but separate notions. So: distinguish the meaning of life in general, the meaning of a particular person's life, and the level of meaningfulness of a person's life.

Some salient proposals (in "Western," broadly speaking, societies, such as ours) for meaningfulness-enhancing features include fulfilling God's purposes, loving another or others and having friendships, being in contact with something "greater" than oneself (where this need not be a perfect or divine being, but can include, among other things, ongoing activities such as science, the arts, athletics, and scholarship), leaving a lasting mark through accomplishments, and so forth. Note that many, if not all of the prominent suggestions, involve making important connections, or perhaps, connections of objective value.

Having a meaningful life - a life whose description counts as a narrative - is an all-or-nothing thing. It requires meeting two conditions: (i) non-delusory connection to reality and (ii) freedom. Such lives can be graded on a spectrum of meaningfulness, depending on our evaluation of the mix of meaning-enhancing and meaning-diminishing features of the life. A life that is meaningful can be located on the meaningfulness scale, so long as it meets the threshold specified by the two constraints.

Analytically then there are two moments in the evaluation of lives with respect to meaning. First one determines whether a person's life meets the basic requirements for having a meaning. Next one judges the life's level of meaningfulness in a scalar, not an all-or-nothing way. Meeting the basic constraints on having a meaningful life at all is the gateway to greater or lesser meaningfulness, as determined by an overall evaluation of the meaningfulness-relevant factors.

The abstract structure of this view is similar to my view about the relationship between moral responsibility and (say) blameworthiness. On my view, moral responsibility is the "aptness" to a set of normative responses - judgments, attitudes (such as resentment), and activities (such as punishment). Moral responsibility is the "gate- 
way" to such responses, and it requires meeting certain basic epistemic and control conditions. Once these are met, there is a further evaluation of praiseworthiness and blameworthiness, and the application of the responses in question in a particular situation. Both views - about moral responsibility and meaning in life-involve two analytic steps, the first of which is all-or-nothing, and the second scalar. (For simplicity's sake I am putting together judgments of [say] blameworthiness and whether the expression of blame is justified in a particular context; they are strictly speaking analytically separate scalar judgments.)

A person "writes" her narrative by acting freely. (I deem "acting freely" to be the freedom component of moral responsibility.) As with any author, she uses material from various "sources" in writing - she does not write in a vacuum. Others give important content to our stories, and then we stitch them together and give them a shape. A free action (an action where the agent acts freely) corresponds to a sentence in the narrative of one's life.

In acting freely, one does not necessarily express a character trait or propound into public space a value for which one stands. For example, one may exhibit weakness of will, deception, or other failures of practical reasoning or its implementation in action. Rather, one adds an element to the narrative of one's life — an element whose meaning interacts with other elements in a distinctive way. We can explain why there is no single meaning of human life in general by noting that there is no single agent (individual or group) who freely and intentionally acts so as to write a narrative of the human species.

I accept David Velleman's (1991, 2003) view that a narrative (strictly speaking, that is, not a mere story or chronicle) has three characteristics: it is apt to elicit an affective or emotional reaction in an appropriate audience, it features meaning holism (the meaning or value of one part can depend on its relationship to others), and it gives a distinctive kind of "totalizing" explanation of the life. A totalizing explanation yields an understanding of the whole life, and its parts, in terms of its ending.

In an important way the meaning of an individual's life pulls apart from considerations of relative meaningfulness of lives: more or less meaningfulness is not a matter of better or worse narrative value, in any sense of "narrative value." A better story (better "in the telling") does not make for a more meaningful life. Neither does more or richer meaning holism. The features in virtue of which the chronicle of an individual's life is a narrative do not bear directly on the degree of meaningfulness in a life, even though they endow the life with a specific meaning. Narratives tell the unique stories of individuals' lives, and they can be placed on a scale of meaningfulness (relative to the consensus of a given social group or society).

It is an interesting question (that I explore in less detail than it deserves) to what extent we need to understand meaningfulness in terms of doing rather than being. Often being active rather than passive is prized in discussions of meaningfulness in human lives - we don't want to be slothful couch-potatoes or "blobs," to use Susan Wolf's (2010) term. We do not however think that a Zen Buddhist monk's life necessarily scores low on the meaningfulness scale. It is thus important to think more carefully about the distinction between activity and passivity. I (Fischer 2021 [a], 2021 [b]) believe that there is an active sense of "being," by reference to which we can deem 
the Buddhist monk's life relatively meaningful and distinguish it from those of some (but not all) couch-potatoes.

\section{Why Is Death Bad, and Should We Fear It?}

Many of us fear death, and sometimes this is a central fact of our lives. When we think carefully about death, however, it is puzzling how it can be a bad thing for the deceased. She's not around anymore, and if it were not a bad thing, she shouldn't fear death at all. These puzzles about death's badness give rise to a strategy pioneered by Epicurus for alleviating our anxieties about death (given a secular framework). The Epicurean strategy is further developed by Lucretius and also by various contemporary philosophers, including Nussbaum (1994).

\section{Epicurean Challenges}

The Epicurean contends that death cannot be a bad thing for the individual who dies, because there is no individual left to be the subject of this purported misfortune. The point that there is no individual left implies that the status of being dead (as opposed to the process of dying) involves no unpleasant experiences on the part of the individual who dies. The Epicurean thus contends that it cannot be bad for her. Also, unlike other harms, it doesn't seem that there is a time at which the badness of death occurs. At the time of being dead, there is no subject of the harm left: and when the subject still exists, the harmful state of affairs has not yet begun to obtain. Epicurus's famous "rallying cry" is: "When the person is, death is not, and when death is, the person is not."

Lucretius offered another argument in defense of the Epicurean position. He pointed out that our being dead and our status before we were born appear to be metaphysically symmetric ("mirror images"): they are both extended periods of nonexistence, and late birth and early death appear to be parallel. Given this metaphysical symmetry, it seems that we should have psychological symmetry-symmetric attitudes toward these two periods. On this view, since we don't regret the time before we were born, we should not (say) fear death. The Epicurean concludes that death is nothing to fear.

I suppose it would be nice if these Epicurean points were uncontroversial and decisive, since they would provide comfort. This is, however, a bit optimistic, and some would even say, "wishful thinking." I consider several ways of responding to the Epicureans, many of which are quite cogent. I contend, however, that there are important grains of truth in their views - insights that might be missed if one dismisses their arguments too abruptly.

\section{The No-Experience Problem}

I believe that various things can be bad for an individual, even though she doesn't have negative experiences as a result: experience is not all there is to harm or badness (just as it is not all there is to goodness). I thus reject "experiential ethics," and, more 
generally, the view that all kinds of value can be reduced to, or defined in terms of, experience.

I consider at some length an example offered by Thomas Nagel (1970). In this case an individual is betrayed behind her back by people who present themselves to her as friends. Perhaps they have regular "meet-ups" where they attack her scurrilously, accusing her of cheating on her partner, plagiarizing her writings, and so forth. The woman however never finds out about these meetings and is otherwise unaffected by them (even indirectly). I agree with Nagel that this sort of case indicates that one can be harmed by something - a bad thing can happen to one-even in the absence of any unpleasant experience caused by it. This is a first step toward defending the notion that death, conceived as an experiential blank, can be bad for the deceased.

The Epicurean however will not be convinced, because there is an important difference between the betrayal case and death: one could find out about and be affected (experientially) by the betrayals, but when dead the individual cannot (by hypothesis) have any negative experiences. This reveals a gap in the argument against Epicureanism based on the betrayal example.

I build on Nagel's example by constructing a related case in which it is impossible (in the relevant sense) for a betrayed individual to find out about the "meet-ups" or be otherwise affected by them. In this sort of example, there is a "counterfactual intervener," White, standing by, ready to block any information about the betrayals from reaching the individual in question. If someone were to seek to call her, the cell phone number would be blocked, if someone were to come to the door, the security system would be triggered, and so forth. We stipulate that everything in the "actual sequence" involving the betrayals is the same in both the original case and the modified case (including White). I contend then that if the individual who is the target of the scurrilous verbal attacks is harmed in the original case, she is also harmed in the modified case. Harm is an "actual-sequence" notion.

The case involving the counterfactual intervener, White, is parallel in structure to the widely discussed "Frankfurt-style Cases" (FSCs), which involve the counterfactual intervener, Black (Frankfurt 1969). The latter cases have been introduced to impugn the "Principle of Alternative Possibilities" (PAP), according to which moral responsibility for an action requires freedom to do otherwise, and thus to defend the claim that moral responsibility is an actual-sequence notion. Of course, it is controversial whether the FSCs are successful in dethroning PAP, and it is similarly unclear whether the modified betrayal case succeeds in refuting the "possible experience" requirement for harm. You might say that the issues are not Black and White! In the book I do however defend the dialectical efficacy of the modified betrayal case, as I have (elsewhere) defended the FSCs (Fischer 1994, 2010). Both harm and moral responsibility are actual-sequence concepts.

\section{The Timing Problem}

There are some viable options (I resisted "live" options) for specifying the time of the harm of death, including "subsequentism," according to which the badness of death takes place during the time at which the individual is dead. I suggest that "being harmed by death" at a time $t$ (which can be an interval of time) is not a tempo- 
rally nonrelational or intrinsic property of an individual existing at (or during) $t$. For example, Aristotle now has the property of being written about by John Fischer. Thus, the subsequentist need not be saddled with the Problem of Predication- the problem of making sense of the notion that an individual who does not exist at $t$ can have an intrinsic property at $t$. The distinction between "hard" and "soft" properties (and facts), which is important in discussions of arguments for logical and also theological fatalism, is the same as the distinction between temporally nonrelational (intrinsic) and temporally relational (extrinsic) properties (Fischer 1983, 1986, 2016).

In the book I briefly suggest this strategy (employing the distinction between temporally intrinsic and temporally extrinsic properties) for answering the Problem of Predication and thus opening a path to subsequentism, I develop it more fully in an article that complements and extends the treatment in the book. (Fischer Forthcoming(a)). My strategy for opening the door to a more complete defense of subsequentism employs the distinction between the time of the truth of a proposition about a subsequent time and the time of the occurrence of the truthmaker of that proposition.

In his important work on fatalism and free will, John Perry (2004) invokes this distinction to analyze the notion of "fixity" of the past. For Perry a proposition that is true in the past need not be considered "fixed" and out of one's control to falsify until the truthmaker for the proposition occurs. Just as Perry analyzes the fixity of the past by making the crucial distinction, I analyze the time of death's badness in terms of this distinction. This suggests an interesting connection between the literatures on free will and death - one which deserves further exploration.

Note that the propositions in question in the debates about the time of death's badness are comparative and normative. They are about one life (say one in which death is later) being better than another. The already delicate issues pertaining to the timing problem and metaphysical grounding of propositions are rendered more challenging by the need to address such propositions. I am not familiar with a discussion of comparative normative propositions in the metaphysical grounding literature.

\section{The Lucretian Mirror Image Argument}

In the book I argue that there are attractive strategies for responding to Lucretius's Mirror Image Argument: the Parfit-style (1984: 165-166) response, which appeals to a reasonable psychological asymmetry (we care about the future in a way in which we don't care about the past), the asymmetry of (plausible) possibility response (it is relatively easy to imagine a later death, but hard to imagine an early birth), and the preference-thwarting response (death thwarts preferences, while late birth does not).

I discuss a Parfit-style response developed by Anthony Brueckner and me (1986). It insists that we can prescind the metaphysics from the psychology; that is, the metaphysical symmetry noted by Lucretius need not imply a psychological symmetry of the relevant kind. In Parfit's famous thought-experiments involving a patient who is awaiting news in a hospital, Brueckner and I "switch out" news about a painful surgery and replace it with a pleasant drug-induced experience. The examples show that, other things equal, we prefer our pains in the past (Parfit's example) and pleasures in the future (Brueckner's and mine). Since early death deprives us of future pleasures 
whereas late birth deprives us of past pleasures, we care more about early death. Here metaphysics does not drive psychology; the metaphysics is symmetric, whereas the psychology is (and arguably should be) asymmetric.

The asymmetry of plausible possibility response, suggested by Nagel (although he also worries about it), holds that there is indeed a metaphysical asymmetry: whereas it is plausible that an individual (the very same one) can live longer than she actually does, it is not plausible that she (the very same individual) could have been born significantly earlier than she actually was. This provides a different response to Lucretius, although the two strategies of response are entirely compatible.

Another (also compatible) response to the Lucretian Mirror Image Argument is suggested by Bernard Williams's (1973) account of why death is bad. Williams rejects the deprivation theory of death's badness on behalf of a "preference-thwarting" model. Accepting this approach, one could say that early death thwarts "categorical preferences" (to pursue projects that give one reason to continue living), whereas late birth does not (insofar as there are as yet no projects to thwart). I hold that this is also a promising avenue of response to Lucretius, worthy of further consideration.

I note here a final strategy of response, not explored in any detail in the book - the Asymmetry of Causal Power approach. Since we can causally affect the future but not the past, it makes sense to focus our practical reasoning on future possibilities, rather than the past. This asymmetric psychological orientation complements the Brueckner/Fischer point that this confers significant survival advantages. Insofar as an advantage in natural selection offers (part of) a rational justification, our future focus is shown to be (at least to some extent) rational, and not just a descriptive psychological feature of human beings.

\section{The Deprivation Theory of Death's Badness and Fear of Death}

Why is death bad for the individual who dies, when it is indeed bad? An influential view is the deprivation account of death's badness, according to which (roughly speaking) death deprives the deceased of goods she would have had, but for her early death. These goods would have made that life (in which she lives longer) better than the life she actually leads. Typically, premature death is bad because it both deprives the individual of good experiences in the future (as part of what would have been an on-balance better life), and it thwarts preferences to pursue projects that give meaning to life. When only one condition is met, death is bad to some extent; when both are met, death is bad in a stronger sense. This shows why the death of a nonhuman animal can be bad to some extent, whereas only the death of a human being (or person) can be a tragedy for the deceased.

I follow others, including Draper (2013), however, in distinguishing between judging that it is a bad thing that one dies prematurely and fearing this possibility. This is an important distinction, and it must be emphasized that the Epicureans were more concerned with diminishing fear than expunging negative judgments. Given that death is a non-experiential bad, it is very different from boredom or torture. We can take at least some consolation from this. It seems to me that fear is keyed to 
unpleasant experiences, whereas our judgments about harms are not constrained in this way.

If all of this is correct the Epicureans are at least partly vindicated, and the insight could be an important part of a secular strategy for terror management (as I note below in my discussion of near-death experiences). The partial vindication pertains to fear, rather than judgments of badness. Whereas I argued in the book that it is not irrational to fear premature death (the status of being dead) to some extent, I have changed my views on this particular point - moving toward the Epicurean positionsince it was published.

I wish to sketch some reflections that motivate my new view. Recently I had (minor) surgery that required me to be under general anesthesia for an hour. When I reflect back on that surgery and focus on my status during that hour, I recognize that I had no experiences and, specifically, no unpleasant experiences. I further realize that there would have been no reason prior to the surgery to fear my status during that hour. Of course, I could reasonably have been concerned with whether the surgery would be a success, and even fear that I would never awaken from the anesthesia. I don't think, however, that it would have been reasonable to fear being in the experiential black hole induced by the anesthesia, and there is no relevant difference (as regards fear) between this situation and one in which I would be under anesthesia for a very long time.

Further, I do not see any difference, as regards the relevant sort of fear, between this last situation and one in which I wouldn't exist at all during the period under consideration. From the experiential point of view-i.e., from the "inside," so to speak - there would be no difference. That is, there would be no difference between existing and having no experiences and not existing anymore (and therefore having no experiences). If fear is keyed to unpleasant experiences, there should be no difference with respect to fear. Thus, given that prior to my surgery it would have been unreasonable to fear my period of unconsciousness when under surgery, it would be similarly inappropriate to fear the status of being dead. I will return to my "conversion" on this issue in my reply to Timmerman in this symposium.

Before I move on, I pause here to consider a passage from Samuel Scheffler (2013: 84).

One immediate objection to the [Epicurean] argument is that it seems to imply not only that we have no reason to fear death but also that nobody can ever have reason to wish for death. Imagine, however, a torture victim who is undergoing such horrible agonies at the hands of a sadistic Epicurean that he begs his tormenter to kill him. And imagine that the Epicurean torturer replies: 'So death, the thing you fervently desire, is nothing to you, since so long as you exist, death is not with you; but when death comes, then you will not exist. It does not then concern you either when you are living or when you are dead...'

Scheffler goes on to point out that the torturer's response is "preposterous."

This is indisputably true, but no consequence of the Epicurean view. That view has it that the status of death in itself is not a matter of concern (specifically, fear) to us, but this does not imply that future possibilities for our lives will not be of interest. I 
certainly can hope that my future life will be as good as possible, and if the torture is bad enough, I can hope that the torture will end immediately. If it is evident that the torture will continue, or even continue a long time, I might well prefer an immediate death. This would not however because I prize the status of nonexistence, but because I care about my future life and avoiding terrible pain.

Similarly, some have wondered whether an Epicurean would have any reason to step off a track to avoid an oncoming train whose brakes have failed (an Epicurean Trolley Problem!). If the Epicurean can envisage a good life in her future, she certainly has reason to step off the track, but not because of the necessity of avoiding the status of being dead.

It is also odd that Scheffler refers to the torturer as an "Epicurean Torturer." Charitably, this is probably not meant to be taken seriously. In any case, it makes sense only if an Epicurean must be an egoist, but this is not so. The Epicurean can care about what happens to her loved ones, potential torture victims, or the planet, for that matter, after she dies. She may, for example, make out a will or establish a trust for her loved ones. This would be because she now cares about how they will fare in the future, not because she will suffer after she has died if they unjustly struggle or be able to appreciate their flourishing. Epicurus held that one can have a range of reasons for action that affect the future, but these reasons don't pertain to one's positive or negative experiences during the period of being dead. There is nothing in the core Epicurean doctrine that "death is nothing to us" that implies that one cannot care about others (now and even after one dies). This point holds apart from any views of Epicurus himself, although Epicurus did commend the moral virtues and recognized the need for justice.

\section{The "Forever" Wars}

If death is indeed bad, would immortality be good? From the beginning of human existence, we have had a profoundly ambivalent attitude toward immortality. In his famous treatment, Gerald Gruman (2003) distinguished between "prolongevists" and "apologists." Roughly speaking, the prolongevists are "pro-immortality," whereas the apologists are anti-immortality. I have proposed a related, but slightly different, distinction between immortality optimists and curmudgeons.

I distinguish Immortality Curmudgeons, Optimists, and Realists. This refinement is rendered necessary in part by contemporary environmental crises. The Curmudgeons, most notably Bernard Williams (1973) in contemporary philosophy, argue that no form of immortality is worthy of choice by human beings, in virtue of basic facts about human character. His main thesis is that any human being would eventually become bored in an immortal life. Bernard Williams has done more than anyone else to propel discussions of the potential desirability of immortality into contemporary discussions in analytic philosophy. He is, you might say, the Chairman of the Bored, to borrow a phrase from the otherwise forgettable Iggy Pop song, "I'm Bored."

The Optimists deny this contention of the Curmudgeons, and they further claim that it is likely (and, for some theorists, highly probable) that human beings will achieve the status of immortality in the not-so-distant future (with a range of not- 
so-distantness). The Realists reject the fundamental contention of Williams and the Curmudgeons, but they also disagree with the Optimists about the likelihood that we will achieve immortality (soon or perhaps ever). Their view is bleaker about the future of our increasingly fragile environment.

Since it is a view involving probabilities, there is a range of Realist views. I am an Immortality Realist. I hold that it is less likely than not that humans will be able to achieve a sustainably life-supporting environment into the future. Not impossible, but maybe only about $30 \%$, so we have to get at it! The Immortality Realist has a healthy concern for the future of the human race - a worry that can result in action to save our planet.

\section{The Immortality Curmudgeons and their Concerns}

Daring to fire some salvos in the "Forever" Wars, I consider a panoply of arguments offered by the Immortality Curmudgeons, who are certainly in the majority among philosophers (historically and now). A large majority of philosophers (especially in contemporary discussions) are dreary spoil-sports about immortality! Such arguments include the worry that an immortal life would lack "form," that it could not correspond to a narrative, that it would not have the stages required for a recognizably human life, that an infinitely long life cannot be grasped by the human mind, that such a life could not be the life of a single human individual, that it could not be "fraught" and thus precious, and that it would necessarily be boring. I find none of them persuasive, although I respect the worries. In particular, I remain cognizant of the difficulties of imagining and thus accurately evaluating, an immortal life, because so many features of our lives, as we know them, would have to be very different. I concede that we need to drive carefully in this terrain and respect reasonable philosophical speed limits.

In considering the Curmudgeons' arguments, I emphasize an important distinction made by Steven Cave (2012). He distinguishes "medical immortality" from "true immortality." If one is medically immortal, one will not die of "natural causes," including diseases or (say) biological degradation caused by aging. Even so, one would be vulnerable to death by accidents, homicidal actions of others, and so forth. One expert estimates that nowadays medical immortality would be about six thousand years. That's a (somewhat informed) guess as to how long (on average) a human being who is medically immortal (but not truly immortal) would last before he accidentally walks off a cliff, is involved in a fatal car accident, murdered by an assailant, and so forth.

A truly immortal individual is invulnerable to death and knows it. (This would seem to imply that he could not take steps to end his own life, which introduces difficulties.) In the book I contend that many of the Curmudgeons' arguments depend on the assumption that the sort of immortality under consideration is true immortality, rather than medical immortality. The dialectic changes dramatically when we switch to medical immortality, which is, after all, the sort envisaged in Bernard Williams's (1973) famous example of Elina Makropulos.

Elina can take an elixir that will ensure that she not die of diseases or aging for 300 years, at which point she again faces of decision about whether to take the elixir. 
There is no indication in the play or opera in which Elina appears that this elixir would render her truly immortal — invulnerable to death by any cause-for 300 years. Much of the discussion in the contemporary literature spawned by Williams's classic paper is insufficiently attentive to the different challenges posed by medical and true immortality. Indeed, it is striking that some philosophers who employ the Makropulos case to introduce their worries go on to present arguments that target a different sort of immortality - true immortality!

As I pointed out above, many contemporary philosophers are Immortality Curmudgeons. I feel sometimes as if agreement with Bernard Williams on this point is a knee-jerk reaction among the philosophical cognoscenti. In one salient example (ed. Kolodny: 2013) of this "kumbaya_-singing," Samuel Scheffler, Niko Kolodny, and Seana Shiffrin all express their agreement with his conclusion, although not necessarily his argumentation.

Not all well-known and highly respected philosophers however are Curmudgeons. Thomas Nagel (2014: Sect. 3) writes:

Couldn't [immortal lives] be composed of an endless sequence of quests, undertakings, and discoveries, including successes and failures? Humans are amazingly adaptable, and have developed many forms of life and value in their history so far... I am not persuaded that the essential role of mortality in shaping meaning we find in our actual lives implies that earthly immortality would not be a good thing. If medical science ever finds a way to turn off the aging process, I suspect we would manage.

\section{Immortality in an Afterlife}

There are different routes to immortality: secular and religious. I argue that many of the same issues arise as to the potential desirability (and even coherence) of secular and religious immortality. One might say that Mark Twain ([original date unavailable]/1970) is to skepticism about the desirability of religious immortality (in some sort of "afterlife") as Bernard Williams is to skepticism about that of secular immortality. Of course, Twain expresses his worries in a considerably less rigorous (although more colorful) way than does Williams! He laments the singing of hymns and waving of palm branches as a terrible way to spend eternity, expresses his preference for the company in hell (despite the better weather in heaven), and so forth. I argue that the responses to the Secular Curmudgeon are in many instances parallel to promising responses to Religious Immortality Curmudgeons. It is noteworthy that the arguments and responses are parallel.

For instance, I have invoked the possibility of "repeatable" pleasures as one (although not the only way) of resisting the contention that secular immortality would necessarily be boring. One does not have to sing hymns or wave palm-branches! This point has an analogue in the view of heaven presented vividly in the Koran, which is described as containing numerous sensual delights. I highlight the fact that many of the concerns about the recognizability and desirability of secular and religious 
immortality are similar, and the resources available to address them are also similar in interesting ways.

Of course, the specifics are different in the two contexts - secular and religious. Religious immortality in the monotheistic Western tradition is true immortality, not mere medical immortality. Arguably religious views that involve reincarnation posit medical immortality (at least as regards bodily death, as "currently" embodied). The recognizability problem emerges in religious immortality if we suppose that we (our souls) are literally "united" with God in an afterlife, or if we imagine resurrection as the relevant sort of communion with God. As regards reincarnation, it not obvious how I- the very same person - could start a different life as a member of another species.

\section{Near-Death Experiences: Supernaturalism}

Many, including (somewhat) scholarly writers on the subject, think that near-death experiences (NDEs) are a portal into immortality in the religious sense. They adopt the doctrine of "supernaturalism about NDEs," according to which our minds are nonphysical (the doctrine of dualism - typically substance dualism), separate from our bodies in NDEs, and travel toward an otherworldly realm. To clarify, the supernaturalist does not contend that NDErs merely have experiences as of their minds or "souls" separating from their body and traveling toward an otherworldly realm. Rather, she holds that NDErs' minds actually do separate from their bodies and actually do travel toward (and sometimes even reach) such a realm.

I canvass a suite of arguments for supernaturalism about NDEs. These include (but are not limited to) the contention that in NDEs people have conscious experiences when their brains are "offline"; that NDEs have similar content (at an abstract level) across persons, cultures, and times; and that some occur in contexts in which the NDErs accurately report verifiable contents that could not have been acquired via naturalistic means. I find them unpersuasive.

\section{When?}

It is a staple of the NDE literature that NDEs take place when the brain is "offline" in the sense in which it could support consciousness (as opposed to the biological "housekeeping" tasks). This "NDE Timing Problem" plays a big role here, as in the discussion of the time of death's badness. It is however totally unwarranted to conclude from the science, together with the NDE reports, that the conscious episodes experienced in NDEs take place when the brain could not have supported consciousness.

The primary reason for this is that, just as with dreams, their contents may not be presented as having taken place at the time at which the brain activity that plausibly supports the episode occurs. So, for instance, it is very plausible that the conscious stream of episodes in a dream take place as the brain is ramping up for awakening. Although this is when the episodes actually take place, it is typically not the time interval during which the depicted events are represented as taking place. There is 
simply no evidence here that conscious episodes take place when the brain cannot underwrite consciousness - so no evidence of dualism (in any form). Further, nearly all neuroscientists conclude that it is almost certain that consciousness does not survive the death of the brain. (One might say that NDErs are "woke!")

\section{Why Universality of Content?}

NDEs have similar content across cultures and times, although the specific details are different and to some extent culturally determined. They typically contain some (but not necessarily all) of the following: an out-of-body experience, travel toward another (otherworldy) realm guided by deceased loved ones and/or religious figures, vivid colors and lucid imagery, ascension from darkness toward light, awakening just prior to making contact with the protected realm, a life review, and so forth.

Why this relatively abstract similarity of structure and content? The supernaturalists contend that it is because NDErs are in contact with a single otherworldly realm (heavenly or hellish). This however ignores the inconvenient differences in the contents of NDEs - some see Christian religious figures, some Hindu, some ride on the wings of butterflies, and so forth. If they are all grasping a single otherworldly realm, why the significant differences in specific contents?

The supernaturalist interpretation also ignores the fact that human beings have certain commonalities that can explain the similarity in contents of NDE reports. Our brains are similar. It is also relevant that human beings generally (although not universally) undergo similar psycho-social development, and we all have similar basic psychological tendencies. This kind of multifactorial naturalistic explanation can explain the general similarity in content, as well as the differences in details. We need not posit contact with a single otherworldly realm to explain the patterns in NDEs. We can more productively attend to features of the experiencer, rather than the putative object or cause of the NDE. The proponents of supernaturalism have "tunnel vision," so to speak!

\section{How do NDErs Know?}

There are numerous veridical reports by NDErs of information that apparently could not have been acquired via ordinary naturalistic means. They are instances of what NDE researchers call "apparently non-physical veridical perception." The supernaturalists place great weight on the fact that they are veridical, often using terms like "extraordinary" and "remarkable." It is however not so extraordinary or remarkable that of the millions of NDE reports, some not insignificant number of them turn out to be true. It would indeed be surprising if the "apparently non-physical" part were actually non-physical, but this is much more difficult, if not impossible, to establish. One could be confused if one's sole or even primary focus were on the veridicality of such reports, rather than their putatively non-physical means of generation.

Supernaturalism is a potent strategy of terror management. The intellectually and emotionally intoxicating cocktail of terror management and confirmation bias is indeed strong, but all the arguments for supernaturalism are unconvincing. The literature on NDEs - both popular and "academic" (published by MDs or PhDs in 
arguably scholarly books and journals) — is replete with pseudo-science and riddled with non-sequiturs (Mitchell-Yellin and Fischer 2014, Fischer and Mitchell-Yellin 2016, Fischer Forthcoming(b)). It is however not surprising that the supernaturalist books sell millions of copies (and make the authors rich in dollars, if not insights), given the powerful terror management they offer and the human tendency toward confirmation bias.

After all, who wishes to read the judicious and skeptical reflections of an analytical philosopher, when one can read about the adventures of a neurosurgeon exploring a beautiful and compelling heavenly realm, flying on the wings of a butterfly? Many cling to what is comforting to them as they consider the prospect of death, and they do not wish to have this comfort threatened or etiolated in any way. The stakes are too high, and the comfort too great. Hence the not-so-peaceful responses to those who dare to challenge the supernaturalist orthodoxy by people who have allegedly imbibed the enlightenment offered by NDEs! I'm tempted to ask, "Where's the peace, love, and understanding?"

I do not primarily seek terror management, but rigor antemortis, so to speak-an analytical rigor sadly lacking in much of the literature on NDEs. I do not however embrace NDE Denialism, the view that people do not have the NDEs they report. I believe that people really have NDEs with the contents they report, but that these contents are not necessarily literal and accurate depictions of external reality. As with my position of Immortality Realism, I am an NDE Realist.

As with my views about immortality and NDEs, I (Fischer 1994, Fischer and Ravizza 1998) take a "middle path" in my account of moral responsibility. I (and my co-author) argue that the freedom-relevant component of moral responsibility is "guidance control," which involves a certain kind of "reasons-responsiveness." The sort of reasons-responsiveness in question is not strong, nor weak, but "moderate reasons-responsiveness." (Fischer and Ravizza 1998) Further, my account of guidance control is squarely in between the requirement of alternative-possibilities freedom ("freedom to do otherwise") and no requirement of freedom of any sort, a view attributed to Peter Strawson. (1962). I agree with Gautama Buddha's insight that the middle path is often the path of wisdom.

As I explain in the next section, the NDE realist can explain the awe-inspiring and transformative capacities of NDEs by reference to a story that these experiences tell-a story that does not imply or presuppose supernaturalism. The beauty of NDEs can be captured in a naturalistic framework, which I present in the book and continue to develop in subsequent work (Fischer 2020[a], 2020[b], 2020[c]).

\section{Near-Death Experiences, Naturalism, and Meaning}

For the supernaturalist, the story of NDEs is a story of separation from one's body and travel toward (and sometimes into) an otherworldly realm. The stories purportedly show, as in the title of a prominent book, that "heaven is for real." They offer a "proof of heaven." These interpretations select only parts of the reported contents of most NDEs, and they interpret them literally. They offer a supernaturalist strategy for managing the terror we feel when considering death, and a view of meaning in life as 
alignment with an other-worldly being. The stories, interpreted in this way, are literally about the trip of an "after-lifetime" (Fischer 2020[c]).

In contrast, I focus on the totality of the reported contents, including their depictions of journeys from the known to the unknown, guided by a loving mentor, in search of an important connection. Further, I interpret the stories metaphorically. In the book I contend that we are deeply moved by the stories NDEs tell because of the centrality in our lives of voyages of discovery-journeys that take us along paths from the known to the unknown, guided by more experienced mentors and loved ones, toward an important connection. Taken literally, the contents of NDE reports do indeed depict a trip of an after-lifetime. I contend that it is more fruitful to interpret them metaphorically, and to home in on the "trip" part, rather than the "after-lifetime" part. Often spiritual experiences are described as "journeys" or "trips" (especially when induced by psychedelic substances), and NDEs are paradigmatic spiritual experiences.

This gives a naturalistic explanation of the deep meaning and transformational power of NDEs, insofar as we affectively "recognize" this sort of journey, which is featured at various points in human life. NDEs tap into an emotional template that is deep and profound in human life. They speak to us in ways that capture our attention and can result in lifelong transformations. My point: we do not need to adopt a supernaturalist interpretation of NDEs to explain their deep meaning and transformational potency.

My interpretation offers a different sort of approach to terror management. When we are anxious about "death," sometimes we are thinking of death as the last part of dying, which can indeed be painful and lonely-quite frankly, worthy of fear and even terror. Our deaths however do not have to be full of pain and loneliness. The story NDEs tell is a story of loving guidance. In facing the most daunting part of our journey - from life to death — we need not be alone. One of the chief lessons of NDEs is that we should move toward more humane ways of dying, rather than continue the practice of extending life indefinitely in sterile and insolating institutional settings.

On my interpretation, the terror management offered by NDEs is about "death" in the sense of the last part of dying, i.e., the transition from being alive to being dead. It is not about the status of being dead. We can however employ this moral of NDE stories as an important part of an overall secular terror management strategy, which combines a more humane way of dying with Epicurean insights into the status of being dead. Supernaturalism has no monopoly on terror management. The famous psychiatrist Irving Yalom (2009) employs Epicurean ideas, especially about the status of being dead, in his clinical practice.

Besides terror management, another of the basic drives mentioned at the beginning of this piece is seeking meaning in life. NDEs model the core of meaningfulness in life: the importance of making valuable connections. After all, NDEs depict a journey toward a protected realm, guided by a loving mentor, in search of a connection of ultimate value. The stories of NDEs thus point to strategies for achieving meaning in our lives.

Return to the relationship between the theory of free will and moral responsibility and that of meaning in life. Throughout my career, I have sought to give a naturalistic account of moral responsibility (and its associated free agency) in terms of 
"guidance control," which is a certain kind of agent-owned reasons-responsiveness. An individual can act from their own reasons-responsive capacities in a naturalistic world. When I act from my own, reasons-responsive mechanism, I do it my way. Free agency and moral responsibility involve a distinctive kind of guidance: active guidance in which the individual seeks to connect with reasons (Fischer 1994, Fischer and Ravizza 1998).

As I've pointed out above, NDEs tell the story of guidance by loved ones from the known to the unknown, with the goal of forging a valuable connection. Active, "initiating" guidance is central to moral responsibility, and trusting acceptance of loving guidance is part of the stories of NDEs. Meaningfulness in human life in its various aspects, then, emerges from this combination of active initiation of guidance and trusting acceptance of it. We might say: meaning in life comes from guidance toward important connection. Perhaps the most basic element in both the active and passive context is guidance: exhibiting guidance control and accepting loving guidance.

Why is guidance the key element in these central normative dimensions of human life? This is a very difficult question, and I hesitate even to attempt an answer. I will however venture to do it, with the understanding that this is merely a tentative idea for consideration. It is meant simply to be suggestive.

Many philosophers in both the literatures on free will/moral responsibility and meaning in life have pointed out that human beings are "in between" God (as conceptualized by "perfect being theology) and nonhuman animals. (I do not here assume that such a God exists; rather, I'm simply working with the concept.).

Harry Frankfurt (1971: 14) writes:

The concept of a person, then, is not only the concept of an entity that has both first-order desires and volitions of the second order. It can also be construed as the concept of a type of entity for whom the freedom of its will can be a problem. This concept excludes all wantons, both infrahuman and human, since they fail to satisfy an essential condition for the enjoyment of freedom of the will. And it excludes those suprahuman beings, if there are any, whose wills are necessarily free.

Gary Watson (1975: 220) puts the point in a slightly different way:

The truth, of course, is that God (traditionally conceived) is the only free agent, sans phrase. In the case of God, who is omniscient and omnipotent, there can be no disparity between valuational and motivational systems. The dependence of motivation and valuation is total, for there is but a single source of motivation.... In the case of the Brutes, as well, motivation has a single source: appetite and (perhaps) passion. The Brutes (or so we think) have no valuational system. But human beings are only more or less free agents [insofar as they have both valuational and motivational systems].

These two famous agency theorists point out that we human beings are the only beings with two potentially conflicting subsystems of (or perhaps inputs to) practical reasoning: in Frankfurt's case, higher and lower-order desires and in Watson's, 
mere desires and values. The challenge for a free agent is to "secure conformity" (in Frankfurt's phrase) between the two subsystems. In contrast, neither God nor nonhuman animals has this challenge, since they have only one subsystem in their practical ecologies.

I pause to note an anomaly in Frankfurt's view_or perhaps it is simply a feature. He contends that God cannot be construed as a person, since His will is necessarily free: securing a conformity between his second-order volitions and first-order desires (if He has them) does not even arise. Frankfurt might be correct about this, but it conflicts with an influential view that God is a person. The reasons why some think of God as a person, and their relationships to God as "personal," typically have nothing to do with the structure of God's will. Although I cannot explore this issue in depth here, I simply note that it either shows (as Frankfurt contends) that, upon reflection, God is not a person, or that Frankfurt's account of the concept of personhood is problematic.

Richard Taylor (1981/2019: 777), whose topic is meaning in life (rather than agency), contends that we have an intermediate status with respect to the creation of meaning:

God, we are taught, did not merely come upon all this and decide to make it his own through sheer power. Instead, he created it all, we are told, and really if for this reason alone thought to be God. We are not gods, but we are not just animals either. We need not stagger dreamlike through the four stages of life to death, accompanied by a series of trivial thoughts... We can instead... live meaningfully, by creating our own meanings...

We have identified another connection between agency and meaning, and I am now in a position to offer a tentative suggestion about the key status of guidance. A perfect being is static; such a being does not change in some sort of transition toward perfection. It is already perfect in every way. Thus, God (if God exists) does not need guidance from another (and, in particular, a loving mentor or guide). Further, nonhuman animals cannot be guided by reasons qua reasons - they are not "reasonsresponsive." They might be able to guide their behavior by cues in their environment, but not reasons.

Human beings are imperfect. We are broken, all of us, or at least "incomplete," and we strive to "fix" ourselves or achieve a kind of "completion." We are in this sense not static, but dynamic. Unlike God, we need guidance by trusted mentors, who offer us reasons for action. Unlike nonhuman animals, we can guide our actions by these reasons: we are reasons-responsive. Imperfect beings like us generate value and meaning from a complex mix of active and passive guidance. These capacities for active and passive guidance are exquisitely attuned to each other: our trusted and loving mentors provide us reasons for action, and we are capable of guiding our actions by precisely those reasons. It's a hand-in-glove fit.

Acknowledgements I am very grateful to the guest editor, Justin Capes, for supporting and organizing this symposium, and for his thoughtful comments. Thanks also to two anonymous referees for this journal whose comments helped to improve the paper greatly. Prior versions of the contributions to this sympo- 
sium were delivered at the APA Pacific meetings in April 2020 (via zoom). On that occasion Connie Rosati was the third commentator, and I have benefited greatly from her insightful comments. I'm thankful to Becko Copenhaver for suggesting and facilitating this symposium.

Open Access This article is licensed under a Creative Commons Attribution 4.0 International License, which permits use, sharing, adaptation, distribution and reproduction in any medium or format, as long as you give appropriate credit to the original author(s) and the source, provide a link to the Creative Commons licence, and indicate if changes were made. The images or other third party material in this article are included in the article's Creative Commons licence, unless indicated otherwise in a credit line to the material. If material is not included in the article's Creative Commons licence and your intended use is not permitted by statutory regulation or exceeds the permitted use, you will need to obtain permission directly from the copyright holder. To view a copy of this licence, visit http://creativecommons.org/ licenses/by/4.0/.

\section{References}

\section{Note: All references to "the book" in the text of this article are to}

Fischer, J. M. 2020. Death, immortality, and meaning in life. New York: Oxford University Press. Becker, E. 1997. The denial of death. New York: Free Press.

Brueckner, A., and J. M. Fischer. 1986. Why is death bad? Philosophical Studies 50(2): 213-223.

Cave, S. 2012. Immortality: The quest to live forever and how it drives civilization. New York: Crown.

Draper, K. 2013. Epicurus and the value of death. In The metaphysics and ethics of death, ed. J.S. Taylor. 2013, 71-79. New York: Oxford University Press.

Fischer, J. M. 1983. Freedom and foreknowledge. The Philosophical Review 92(1): 67-69.

Fischer, J. M. 1986. Hard-type soft facts. The Philosophical Review 95(4): 591-601.

Fischer, J. M. 1994. The metaphysics of free will. Oxford: Blackwell.

Fischer, J. M. 2010. The Frankfurt Cases: The Moral of the Stories. The Philosophical Review 119(3): 315-336.

Fischer, J. M. 2016. Our fate: Essays on God and free will. New York: Oxford University Press.

Fischer, J. M. 2020(a). Near-death experiences: To the edge of the universe. The Journal of Consciousness Studies 27(11-12): 166-191.

Fischer, J. M. 2020(b). Naturalism and the beauty of near-death experiences. The Journal of Consciousness Studies 27(11-12): 244-263.

Fischer, J. M. 2020(c). Are near-death experiences real? The New York Times: The Stone: Feb 13.

Fischer, J. M. 2021(a). The problem of now. Aeon: 8 January.

Fischer, J. M. 2021(b). We are all here now. The Blog of the American Philosophical Association: February 11 .

Fischer, J. M. Forthcoming(a). When is death bad, when it is bad? Philosophia.

Fischer, J. M. Forthcoming(b). Review of After: A doctor explores what near-death experiences reveal about life and beyond. The Journal of Consciousness Studies.

Fischer, J. M., ed. 1986. Moral responsibility. Ithaca: Cornell University Press.

Fischer, J. M., and B. Mitchell-Yellin. 2016. Near-death experiences: Understanding visions of the afterlife. New York: Oxford University Press.

Fischer, J. M., and M. Ravizza. 1998. Responsibility and control: A theory of moral responsibility. New York: Cambridge University Press.

Frankfurt, H. 1969. Alternate possibilities and moral responsibility. The Journal of Philosophy 66(23).

Frankfurt, H. 1971. Freedom of the will and the concept of a person. The Journal of Philosophy 68(1): 5-20.

Frankl, V. 2006. Man's search for meaning. Boston: Beacon Press.

Gruman, G. 2003. A history of ideas about the prolongation of life. New York: Springer Publishing Company.

Mitchell-Yellin, B., and J. M. Fischer. 2014. The near-death experience argument against physicalism: A critique. The Journal of Consciousness Studies 21(7-8): 158-183.

Nagel, T. 1970. Death. Nous 4(1): 73-80. 
Nagel, T. 2014 (Jan. 9). After you've gone [Review of ed. Kolodny. 2013]. The New York Review of Books: Section 3, pages unavailable.

Nussbaum, M. 1994. The therapy of desire. Princeton: Princeton University Press.

Parfit, D. 1984. Reasons and persons. Oxford: Clarendon Press.

Perry, J. 2004. Compatibilist options. In Freedom and determinism, eds. M. O. O’Rourke, and J. K. Campbell, 231-254. Cambridge: MIT Press.

Scheffler, S. 2013. Fear, death, and confidence. In Death and the Afterlife, ed. Niko Kolodny, 83-110. New York: Oxford University Press.

Strawson, P. 1962. Freedom and resentment. Proceedings of the British Academy 48: 1-25.

Taylor, R. 1981/2019. The meaning of human existence. In Values in conflict: life, liberty, and the rule of law, [pages unavailable], ed. B. Leiser. London: MacMillan. Reprinted in Introduction to philosophy: classical and contemporary readings Eighth edition, eds. Perry, J., M. Bratman, and J.M. Fischer, 761-777. New York: Oxford University Press.

Twain, M. 1970. Mark Twain's Quarrel with Heaven. Lanham, MD: Rowman and Littlefield.

Velleman, D. 1991. Well-being and time. Pacific Philosophical Quarterly 72(1): 48-77.

Velleman, D. 2003. Narrative explanation. The Philosophical Review 112(1): 1-26.

Watson, G. 1975. Free agency. The Journal of Philosophy 72(8): 205-220.

Williams, B. 1973. The Makropulos case: reflections on the tedium of immortality. 82-100. Cambridge: Cambridge University Press.

Wolf, S. 2010. Meaning in life and why it matters. Princeton: Princeton University Press.

Yalom, I. 2009. Staring at the sun: Overcoming the terror of death. San Francisco: Jossey-Dass (Wiley Imprint).

Publisher's Note Springer Nature remains neutral with regard to jurisdictional claims in published maps and institutional affiliations. 